\title{
Qualitative and quantitative determination of chemicals and dust in the air of the work environment
}

\author{
Ada Traumann, Piia Tint \\ Tallinn University of Technology, Ehitajate 5, Tallinn 19086, Estonia
}

\begin{abstract}
A four-stage health risk assessment model for chemicals and dust in the air of the work environment considering the new legislation, new technologies and market demands was worked out in the current study. The boundary lines between the risk levels were derived from the literature and experimental data. The experiments covered shale fuel oil handling, wood processing, opened car washing, and manufacturing of rubber based details for cars.

In the work environment in Estonia, the legislative requirements are usually met and the hazardous and carcinogenic substances have been substituted. The problem arise with new technologies and unpleasant odors of substances during handling. Some workers might be allergic, but others could be disturbed only by the unpleasant odors. Our new four-stage model is based on the standard EN-EVS-15251, but the hazards statements of chemicals were also taken into account. The microclimate conditions influence on the developing the health risk level in the work environment. For example, in the furniture industry, where wood dust is the major risk factor, the disturbances of wood dust on health depend on the microclimate parameters such as relative humidity and temperature. Higher humidity and lower temperature of the air allow to reduce the spread of wood dust. The origin of the specific odor of shale oil (complex mixture) in the air of the work environment is difficult to determine. The workplace air quality depends on the vaporization rate of different toxic compounds, such as cyclohexa-1,3,5-triene, methylbenzene, 1,2-dimethylbenzene, hydroxybenzene etc. The presence of these hazardous substances were measured with the portable FTIR/FT-NIR spectrometer Interspec 301-X with open optical path. The dust concentration was measured with Haz-Dust5000 and particle distribution in wood dust with Fritsch Particle Sizer "analysette 22".
\end{abstract}

Keywords: indoor air; risk assessment; dust; chemicals in the air.

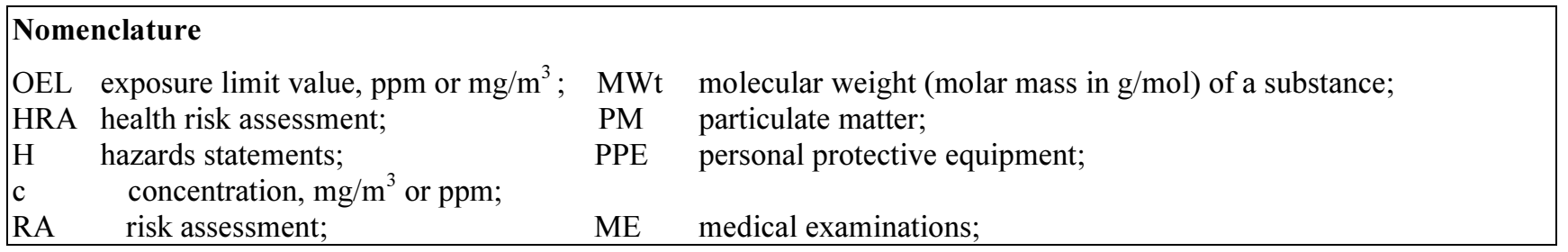

\section{Introduction}

The contamination of environment with hazardous chemicals and dust is continuous [1]. Most of the hazardous substances are emitted to the environment during production and application. To reduce negative impact of chemicals and dust on human health, several legal acts are adopted to regulate the use of hazardous chemicals (REACH). The new term "ecodesign" focuses on the integration of environmental consideration in the product development [2]. On the philosophical level, the "eco-design" is about the reduction of toxicity. There are different types of eco-design tools, but they provide no hazard criteria. Our aim is to remedy this deficiency.

The quality of the risk assessment (RA) of occupational health hazards is a key question for occupational health and safety (OHS) in enterprises and offices. On the basis of the RAs, the workers undergo medical examinations (ME) by the

Corresponding author: Piia Tint. E-mail address: piia.tint@ttu.ee

http://dx.doi.org/10.3846/enviro.2014.064

(C) 2014 The Authors. Published by VGTU Press. This is an open-access article distributed under the terms of the Creative Commons Attribution License, which permits unrestricted use, distribution, and reproduction in any medium, provided the original author and source are credited. 
occupational health specialists and overall, the health of workers depends on the RA quality. The RA in the EU is based on BS8800 and OHSAS 18001. Some simple and flexible models for the RA exist in small and medium-size enterprises [3, 4].

The polluting substances in the air of the work environment have a summation impact on human's health and should not exceed value "one", that is [5]:

$$
\mathrm{C}_{1} / \mathrm{OEL}_{1}+\mathrm{C}_{2} / \mathrm{OEL}_{2}+\ldots+\mathrm{C}_{\mathrm{n}} / \mathrm{OEL}_{\mathrm{n}} \leq 1,
$$

where $C_{1} \ldots C_{n}$ - the values of concentrations of polluting substances identified in the air of the work environment; $\mathrm{OEL}_{1} \ldots \ldots \mathrm{OEL}_{\mathrm{n}}$ - exposure limit values for corresponding substances.

This formula does not take into consideration the specific hazardous properties of the chemical substances and dust (carcinogenicity) and the resulting health disturbances (irritation and dermatitis of skin, asthma and other diseases of pulmonary organs, headaches, and neurological problems).

Workplace exposure limits for volatile substances are expressed or in ppm (parts per million by volume) or in milligrams per cubic metre $\left(\mathrm{mg} / \mathrm{m}^{3}\right)$ of (in) air.

For the conversion of OEL expressed in $\mathrm{ppm}$ to $\mathrm{mg} / \mathrm{m}^{3}$ could be used the following equation [5]:

$$
\text { OEL in } \mathrm{mg} / \mathrm{m}^{3}=\frac{\text { OEL in ppm } \times M W t}{24.05526},
$$

where MWt is the molecular weight (molar mass in $\mathrm{g} / \mathrm{mol}$ ) of the substance; $24.05526 \mathrm{l} / \mathrm{mol}$ is the molar volume of an ideal gas at $20^{\circ} \mathrm{C}$ and at atmosphere pressure equal to 1 atmosphere $(760 \mathrm{~mm}$ mercury, $101325 \mathrm{~Pa})$.

The aim of the paper is to develop a four-stage model for health risk assessment (HRA) considering the new hazards in the work environment that outgrow from the new technologies and handling habits. The investigated modern technologies were: shale fuel oil handling, wood processing, opened car washing, waste recycling of car tires to new products.

\section{Theoretical basis}

\subsection{Risk assessment in the work environment in the case of chemicals and dust}

The assessment of occupational risks in Estonia began in 1998, when the European document „Guidance on risk assessment at work" [6] became accessible. This guidance is tightly connected with the British Standard 8800 (two versions, the first in 1996 [7], the second in 2004 [8]), where the five-stage RA method is presented that did not bind the employer in the determination of the risk level strongly with the exposure limits. This scheme advises the manager to choose the risk level corresponding to the acceptable one that is lower than the tolerable and lower than needed by the exposure limits. Such approach requires awareness, willingness and financial possibilities of the manager.

According to BS 8800:2004 [8], three harm levels (slight harm, moderate harm, extreme harm) on health are determined. The number of risk categories is 5 (very low, low, medium, high and very high risk). Besides, the evaluation of risk tolerability gives 3 possibilities (acceptable, tolerable or unacceptable). The very low risk is considered acceptable, very high risk unacceptable; while the other risks between acceptable and unacceptable (low, medium, high risk) require reduction to acceptable or tolerable level, whereas acceptable is smaller risk than tolerable (Table 1).

\begin{tabular}{|c|c|c|c|}
\hline Severity of harm & $\begin{array}{l}\text { Slight harm } \\
\text { Nuisance and irritation (e.g. } \\
\text { headaches); temporary ill } \\
\text { health leading to discomfort } \\
\text { (e.g. diarrhea) }\end{array}$ & $\begin{array}{l}\text { Moderate harm } \\
\text { Partial hearing loss, } \\
\text { dermatitis; asthma; work } \\
\text { related upper limb } \\
\text { disorders, ill health leading } \\
\text { to permanent minor } \\
\text { disability }\end{array}$ & $\begin{array}{l}\text { Extreme harm } \\
\text { Acute fatal diseases; severe life } \\
\text { shortening diseases; permanent } \\
\text { substantial disability }\end{array}$ \\
\hline $\begin{array}{l}\text { Very unlikely } \\
\text { Experienced at least once every six months } \\
\text { by an individual }\end{array}$ & Very low risk-Acceptable & Very low risk- Acceptable & High risk-Tolerable* \\
\hline $\begin{array}{l}\text { Unlikely } \\
\text { Experienced once every five years by an } \\
\text { individual }\end{array}$ & Very low risk- Acceptable & Medium risk- Tolerable* & Very high risk-Unacceptable \\
\hline $\begin{array}{l}\text { Likely } \\
\text { Experienced once during the working lifetime of } \\
\text { an individual }\end{array}$ & Low risk-Acceptable* & High risk-Tolerable* & Very high risk-Unacceptable \\
\hline $\begin{array}{l}\text { Very likely } \\
\text { Less than } 1 \% \text { chance of being experienced by an } \\
\text { individual during their working lifetime }\end{array}$ & Low risk-Tolerable* & $\begin{array}{l}\text { Very high risk- } \\
\text { Unacceptable }\end{array}$ & Very high risk-Unacceptable \\
\hline
\end{tabular}

Table 1. Risk levels (on the basis of BS 8800:2004)

* Risks that should be reduced as low as acceptable or tolerable level 
The existing RA models (on the basis of BS 8800) contain the need to determine the probability of the occurrence and the severity of consequences of the influence of hazardous factors on worker. It is complicated to determine the probabilities. Therefore, it is commonly used in the case of major accidents. The need for setting the correlations between the exposure and the stages of occupational diseases considering both the exposure time and exposure limits is very obvious. Finnish researchers [9] have proposed a scheme for risk level determination for the hazards originating from chemicals considering exposure limits and considering the exposure time by the Estonian authors [10]. The results are presented in Table 2 ([9] - italic; [10] - bold).

Table 2. Determination of risk level in the case of hazardous chemicals in the air of work environment

\begin{tabular}{|c|c|c|c|}
\hline Consequences & $\begin{array}{l}\text { Slightly harmful }[10] \\
\text { Hyperstenic syndrome } \\
\text { (mild level of asthenia, } \\
\text { irregular speed of mental } \\
\text { activity, deficient ability } \\
\text { to concentrate, increased } \\
\text { number of errors in the } \\
\text { psychological tests) }\end{array}$ & $\begin{array}{l}\text { Harmful [10] } \\
\text { Hypostenic syndrome } \\
\text { (moderate asthenia, } \\
\text { decreased speed of } \\
\text { mental activity, } \\
\text { decreased ability } \\
\text { to concentrate, prolonged } \\
\text { reaction time) }\end{array}$ & $\begin{array}{l}\text { Extremely harmful [10] } \\
\text { Organic psychosyndrome } \\
\text { (expressed asthenia, } \\
\text { memory disorders } \\
\text { of organic type, lowered } \\
\text { visual-constructive } \\
\text { ability, clearly prolonged } \\
\text { reaction time) }\end{array}$ \\
\hline Probability & $\begin{array}{l}\text { Slightly harmful [9] } \\
\text { uncomfortable, irritative } \\
\text { feeling, overcoming } \\
\text { illnesses } \\
\text { R20, 31, 36, 37, } 38^{2}\end{array}$ & $\begin{array}{l}\text { Harmful [9] } \\
\text { burning, skin diseases, } \\
\text { long-lasting severe } \\
\text { damages, stable slight } \\
\text { disturbances } \\
R 23,24,25,33,34,40,43, \\
48,62,63\end{array}$ & $\begin{array}{l}\text { Extremely harmful [9] } \\
\text { poisonings, occupational } \\
\text { cancer, asthma, stable severe } \\
\text { damages, illnesses } \\
\text { dangerous to health } \\
R 26,27,35,39,41,42,45,49,60,61 \text {, } \\
65\end{array}$ \\
\hline $\begin{array}{l}\text { Low }[\mathbf{1 0 ]} \\
\text { duration of exposure } \\
<\mathbf{5} \text { years } \\
\text { Highly unlikely [9] } \\
\text { severe damage from }<10 \% \text { of the limits } \\
\left(O E L^{1}\right) \text {, other } 10-50 \% \text { of the limits }\end{array}$ & $\begin{array}{l}\text { no risk reduction measures } \\
\text { needed }\end{array}$ & follow-up of risks & risk reduction measures needed \\
\hline $\begin{array}{l}\text { Medium [10] } \\
\text { duration of exposure } \\
\text { 5-10 years } \\
\text { Unlikely [9] } \\
\text { Severe damage from } 10-50 \% \text { of the limits; } \\
\text { other } 50-100 \% \text { of the limits }\end{array}$ & follow-up of risks & $\begin{array}{l}\text { risk reduction measures } \\
\text { needed }\end{array}$ & risk reduction measures inevitable \\
\hline $\begin{array}{l}\text { High }[10] \\
\text { duration of exposure } \\
>10 \text { years }\end{array}$ & moderate risk & substantial risk & intolerable risk \\
\hline $\begin{array}{l}\text { Likely [9] } \\
\text { severe damage from } 50-100 \% \text { of the limits, } \\
\text { other over limits }\end{array}$ & $\begin{array}{l}\text { risk reduction measures } \\
\text { needed }\end{array}$ & $\begin{array}{l}\text { risk reduction measures } \\
\text { inevitable }\end{array}$ & $\begin{array}{l}\text { risk reduction measures to be } \\
\text { implemented at once }\end{array}$ \\
\hline
\end{tabular}

${ }^{1}$ OEL - Occupational Exposure limit

${ }^{2}$ The risk phrases have been replaced with hazard statements in the new legislation of chemicals

Table 2 contains two factors: probability (likelihood) of the occurrence and consequences if the harm from a particular hazard is realized. The percentage of exposure limit $(<10 \%, 10-50 \%, 50-100 \%)$ is taken as the probability [9]. Exposure limits are usually expressed as time-weighted, whole-shift concentrations and where necessary, short-term peak concentrations. However, in many cases (for example exposure to neurotoxic hazards) also the exposure time to the chemical has to be considered at low concentrations, not exceeding the limits. The neurotoxic substances can react on the nervous system during long-term exposure to chemicals at low concentrations (Table 2, bold, [10]).

The chemical exposure limits in Estonia give two different numbers: 8 hours' mean concentration in the air of the work environment and 15-minute momentary limit. The norms also identify three levels of hazardousness of the chemical: harmful, toxic, and very toxic [11].

Organic solvents (toluene, styrene etc.) have usually neurotoxic effect. The prevention of chronic neurological occupational diseases is possible in their early detection and exact diagnoses in the early stage of functional disorders. Only then it is feasible to rehabilitate the workers' health and work ability largely. The nervous system is one of the most sensitive systems of the organism that dynamically reacts to various exogenous factors [10, 12]. The syndromes are characterized in three stages (Table 2, bold): hypersthenic, hyposthenic and organic psychosyndrome.

Two different possibilities to determine the health risk level have been proposed [9, 10]. One of them takes into account the exposure level [9] and the other exposure time [10]. They both are too difficult to employers to realise and 
incomprehensible for occupational health doctors to identify risk levels and to prevent necessities. Therefore, a flexible RA method (2.2) was worked out in Tallinn University of Technology [10].

\subsection{A flexible risk assessment method}

A flexible RA method is based on a two-step model (Fig. 1) that could be enlarged into five- to six-level model. The twolevel model has one boundary line (red on the colored scheme), which is a stable and largely spread number such as a norm or standard (OEL). The no/yes principle is used or corresponds to the norms/does not correspond to the norms or justified/unjustified risk. The model also suits small enterprises and to these with simpler combination of hazards or with rather inexperienced personnel (also in work safety).

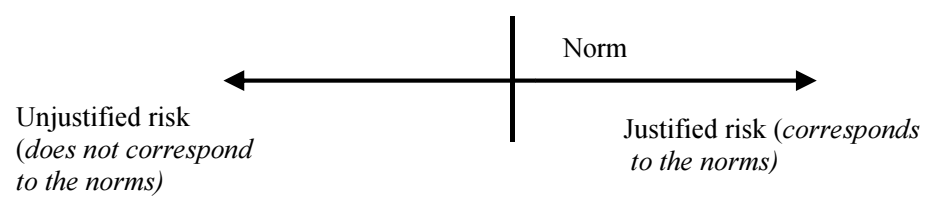

Fig. 1. Two-step model

On the basis of the flexible RA method, a five-step model (presented by Reinhold \& Tint in [4]) has been derived connecting the occupational health diseases ( 3 levels) and the risk levels of dust in the work environment.

\subsection{The model based on EN 15251}

It is shown in $[13,14]$ that the four-stage RA model is suitable to guarantee the comfort of people in offices and schools. According to EN 15251, the hazards determining the comfort class of the office-room are: the temperature and humidity of the air, ventilation rate of the room, the concentration of carbon dioxide, lighting of the rooms, particularly in the modern buildings [13]. We propose that the model could also be used in industrial rooms and for the assessment of chemicals and dust.

The current paper concentrates on the influence of modern technologies (shale fuel oil handling, wood processing, opened car washing, waste recycling of car tires to new products etc.) on human health. These new technologies have been introduced in Estonian industries. These manufacturing or handling processes involved create new hazards in the work and outdoor environments. It is complicated to determine chemicals evaporated into the work environment as the portable equipment has to be used and the chemical phase is usually mixed from different chemicals. Furthermore, it is unknown in advance which chemicals we have to deal with. The problem with wood dust is that new wood types are used (juniper, mahogany) and new technologies and areas of manufacturing (like souvenir preparation, wooden baths etc.) are created according to the market demands.

Before 1985, OSHA regulated wood dust exposure limit as $15 \mathrm{mg} / \mathrm{m}^{3}$ [15]. Nowadays in some countries, there are different OELs for soft wood dust and hard wood dust [17]. However, the distribution of particles is not mentioned. The investigation of dust in the outdoor environment in Estonia [16] have shown that the life-expectancy at birth per resident of Tallinn (the capital) on average has decreased by 0.63 years caused by dust. In the polluted city centres, the average decrease in life-expectancy may reach $>1$ year. Wood dust has irritant, fibrogenic, allergic, toxic, and cancerogenic influence on the body, depending on the physical-chemical properties of dust (structure, shape, amount, solidity, liquidity, explosiveness), concentration in the air of the work environment and duration of impact [17]. Diseases caused by wood dust most frequently affect respiratory organs, eyes, and skin [18].

\section{The aim of the study}

The aim of the study was to work out a new four-stage HRA model with fixed boundary lines between the health risk levels for chemicals and dust in the work environment air of new technologies. The data are derived from the new legislation and experimental investigations presented in the current work. This investigation is urgently needed by the occupational health doctors to prevent the health disturbances of workers caused by their work and to prolong the work-life of people.

\section{Material and methods}

The experiments were carried out during 2011-2013 in different manufacturing activities. The main attention was paid to shale fuel oil handling (in the boiler house) and dust propagation problems in wood processing. 


\subsection{Measurement of chemicals}

The portable FTIR/FT-NIR spectrometer Interspec 301-X with open optical path was used for determination of chemical vapors in the air. Thermo Scientific Nicolet IR100 is the real-time process analyser that enables quantitative determination of 435 different chemicals in the air of the work environment. The overall wavelength range is 7000 to $400 \mathrm{~cm}^{-1}$ (IR). Infrared spectrometers measure the spectrum of light (colors) which is absorbed, emitted or reflected from the test material. The shale fuel oil vaporization properties depend on fuel oil characteristics, like phenolic $\mathrm{OH}$ content, number of average molecular weight and molecular weight distribution. An infrared spectroscope (FT-IR) with an attenuated total reflection (ATR, ZnSe crystal) system was used to characterize fuel oil functional groups and specifically to evaluate qualitatively the phenolic $\mathrm{OH}$ content. For quantification, a correlation was used that relates to the area of the $3600-3100 \mathrm{~cm}^{-1} \mathrm{region} \mathrm{to}$ the phenolic $\mathrm{OH}$ group content of shale oil fractions. Unpleasant odor of shale fuel oil might also be caused from phenols. Unfortunately, we were unable to determine the number of phenol quantitatively, because it is not included in the analyzers database of substances.

Dräger-Accuro Gas Detection Pump is the device of the express method to determine the gaseous components in the work environment air. We can use different indicator tubes for the parallel determination of chemicals that have been detected by FTIR. Comparison of the results improves the accuracy of the results obtained by the spectrometer. The express method helps to determine substances in the air qualitatively.

\subsection{Measurement of dust}

The dust concentration by time was measured with real-time dust monitoring device Haz-Dust EPAM 5000. The Haz-Dust uses the principle of near-forward light scattering of an infrared radiation to immediately and continuously measure the concentration of airborne dust particles in $\mathrm{mg} / \mathrm{m}^{3}$. Particle size range is $0.1-10 \mu \mathrm{m}$. Particles in sizes $>10 \mu \mathrm{m}$ will be kept in the upper respiratory tract and do not threaten the workers lungs [19].

Estonian factories use dust of two types: softwood and hardwood. Softwoods (pine, spruce, juniper) are considered to be coniferous species of wood and hardwoods (birch, alder, mahogany) are deciduous species of wood. The dust of both type of woods have different distribution of particles depended on the handling process (polishing or grinding etc.).

The fine dust is present in the furniture industry. Our aim was to study the distribution of particles connected with sandpapers used in different manufacturing methods. The grit sizes (in micrometres) of the sandpapers used in furniture industry are P240, P180, P 120 and P80. Paper P80 is aimed for phasing, P120 for removing varnish or paint from the wood, $\mathrm{P} 180$ and P240 are mostly used in the furniture industry for sanding.

Fritsch Particle Sizer "analysette 22" was used to determine the wood dusts derived with different sandpapers. A wood dust dispersed at an adequate concentration in the water is passed through the beam of a monochromatic light source, a laser. The measurement of size distributions of particles in any two-phase system based on the standard ISO 13320. The standard is applicable to particle sizes ranging from approximately $0.1 \mu \mathrm{m}$ to $3 \mathrm{~mm}$.

The polarization microscope Axioskop gave 10,000 multiple magnification of wood dust particles (Fig. 5). A microscope focused on the examination of crystalline structures. Using the highest Carl Zeiss standards, the shape and size of the dust particle was determined (from 0.74 to $15.71 \mu \mathrm{m}$ in the case of juniper dust; the mean $6.25 \mu \mathrm{m}$ (SD 5.7)). The distribution for two different wood dusts (juniper and alder) grained by sandpaper P120 was examined.

\section{Results}

\subsection{Qualitative and quantitative study of chemicals in the air of the work environment}

Data characterizing the vapors identified during handling of shale fuel oil are presented in Table 3. From the investigated gases, benzene is carcinogenic, toluene influences the central nervous system, benzene and toluene have also influence on unborn babies and may cause mutagenic effects. Xylene and phenols have effect on skin and if swallowed.

Table 3. Measurement results, odor thresholds, exposure limits, lethal concentrations and hazard statements of investigated chemicals evaporating from shale fuel oil

\begin{tabular}{|c|c|c|c|c|c|}
\hline Hydrocarbon & $\begin{array}{l}\text { Concentration of } \\
\text { chemical in the air, ppm } \\
\text { Dräger/FTIR }\end{array}$ & $\begin{array}{l}\text { Hazard } \\
\text { statements } \\
{[25]}\end{array}$ & $\begin{array}{l}\text { Odor threshold, } \\
\text { ppm } \\
{[23]}\end{array}$ & $\begin{array}{l}\text { Exposure } \\
\text { limit, ppm } \\
{[11]}\end{array}$ & $\begin{array}{l}\text { IDLH, } \\
\text { ppm } \\
{[24]}\end{array}$ \\
\hline $\begin{array}{l}\text { Benzene } \\
\text { (cyclohexa-1,3,5-triene) }\end{array}$ & 1.0/n.i. & $\begin{array}{l}\text { Н225, Н304, Н315, } \\
\text { H319, Н340, Н350 }\end{array}$ & 4.68 & 0.5 & 500 \\
\hline $\begin{array}{l}\text { Toluene } \\
\text { (Methylbenzene) }\end{array}$ & $6.0 / 10.0$ & $\begin{array}{l}\text { H315, H304, Н373, } \\
\text { H361d }\end{array}$ & 1.60 & 50 & 500 \\
\hline $\begin{array}{l}\text { Phenol } \\
\text { (Hydroxybenzene) }\end{array}$ & 20.0/n.i. & H311, H301 & 0.04 & 2 & 250 \\
\hline
\end{tabular}


The concentration of o-xylene measured by Dräger methodic (compared with FTIR/FT) was higher because toluene was also indicated. There was no soft-wear for determination quantitatively the phenols with FTIR/FT device. So both the Dräger express method and the FTIR/FT device are very useful to determine chemicals vapors in the workroom during their handling. The results of measurement by the infrared spectroscope (FT-IR) are presented in Fig. 3 and Fig. 4.

High humidity and water content was found in the air in the environment of the open to outdoors smart-type car washing centre. Therefore, it is complicated to determine different substances, but ethylene was determined using the portable infrared spectrometer. The analysis of the vapor phase of shale fuel oil composition revealed the presence of several hazardous compounds, including toluene, xylene, phenol and carcinogenic benzene, even at room temperatures. Fig. 3 shows the measurement of toluene and o-xylene with an infrared spectrometer.

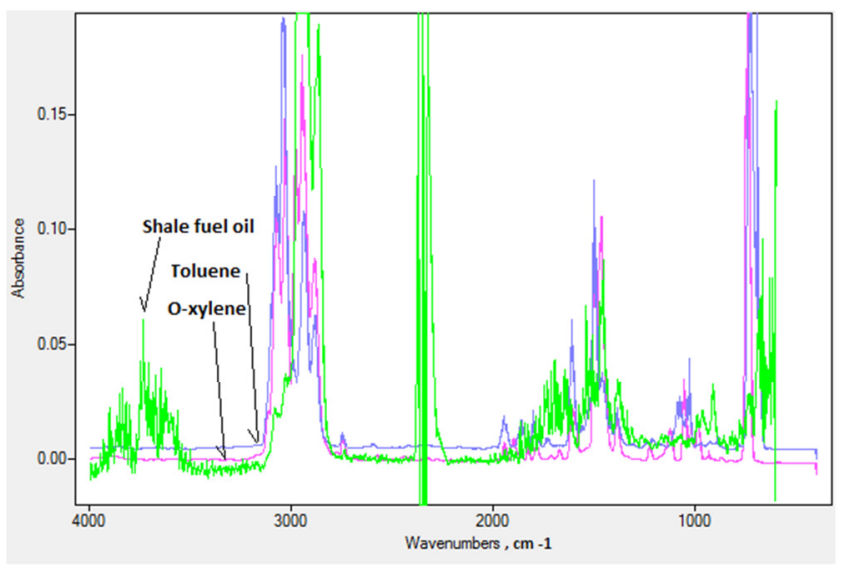

Fig.3. Determination of 1,2-dimethylbenzene and methylbenzene with FTIR/FT

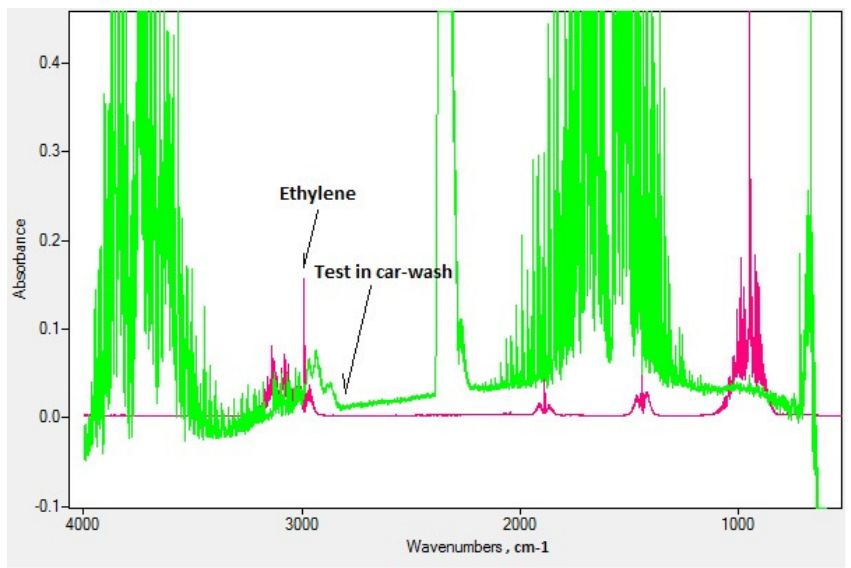

Fig.4. Determination of ethene (ethylene) with FTIR/FT

\subsection{Qualitative and quantitative study of wood dust in the work environment}

The highest dust concentration measured in wood industry, was $4.27 \mathrm{mg} / \mathrm{m}^{3}$. In the glass wool industry it is up to $20 \mathrm{mg} / \mathrm{m}^{3}$. The health risk level is the $4^{\text {th }}$ in this case. The exposure limit for all inhalable dust in Estonia is $5 \mathrm{mg} / \mathrm{m}^{3}$ [11], although for wood dust it is $2 \mathrm{mg} / \mathrm{m}^{3}$. The effective measures for workers' health protection are: effective local exhaust ventilation by all woodworking machines; automated machines; rooms should be cleaned every day, particularly the workplaces with vacuum; ventilation should be balanced by the intake of fresh air.

The magnification on 10,000 times showed (Fig.5) that the particles of wood dust are round rather sharp. The conditions in the wood processing industry in Estonia have been improved compared with the period 1968-1995. Concentration of dust has decreased after the implementation of the compressed air at manual machines, work at fully automatic or semiautomatic machines, vacuum cleaning of machines, exhaust ventilation functioning, and regular daily cleaning of workrooms. From the investigated different Estonian softwood types juniper has the strong smell, but it is used only in small amounts for making souvenirs. The disparity of particles` shape between different type of woods was not observed. The shape is mostly round rather than fibrous (Fig. 5). Therefore, the toxicity of dusts is identified only by the type of wood.

The distribution of particle size is smaller in softwoods ' dust, therefore they are more hazardous for workers. Because of this, the occupational exposure limit (OEL) for dusts is justified to be the same both for soft- and hardwoods $\left(2 \mathrm{mg} / \mathrm{m}^{3}\right)$ regarding to the Estonian legislation [7]. Fig. 6 shows dust concentrations of pine wood and juniper after manual sanding of both woods (changes in sandpaper grit). The difference between the concentration of dust in the air using sandpaper P80 and $\mathrm{P} 180$ is insubstantial. The dust concentrations in the workrooms during testing was between $14-20 \mathrm{mg} / \mathrm{m}^{3}$.

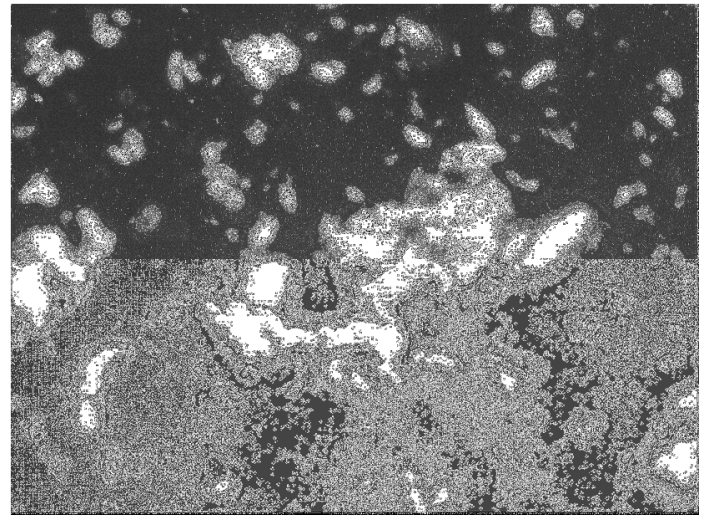

Fig.5. The particles of juniper dust (10,000 magnification)

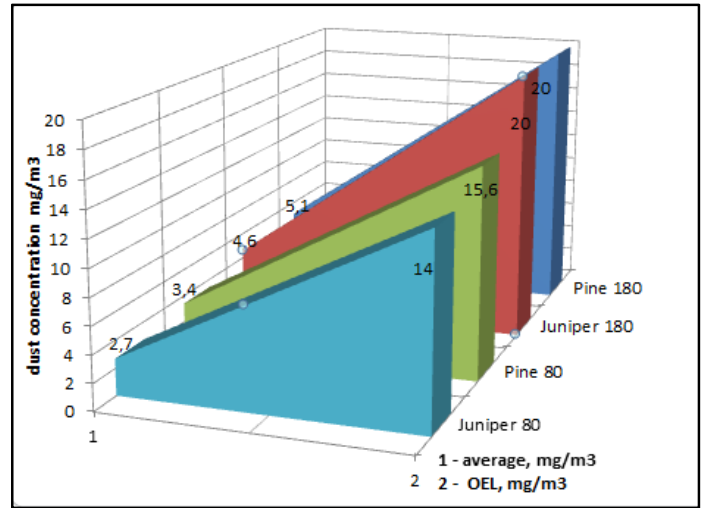

Fig.6. Dust particles concentration with different sandpapers 
Our experiments with dust show that juniper`s dust has more particles in sizes PM10-PM50 compared with pine or spruce dust (Fig. 7, Fig. 8). During the grinding of juniper it was observed that juniper dust was stickier. It sticks to the substrate more than other softwoods, such as pine or spruce.

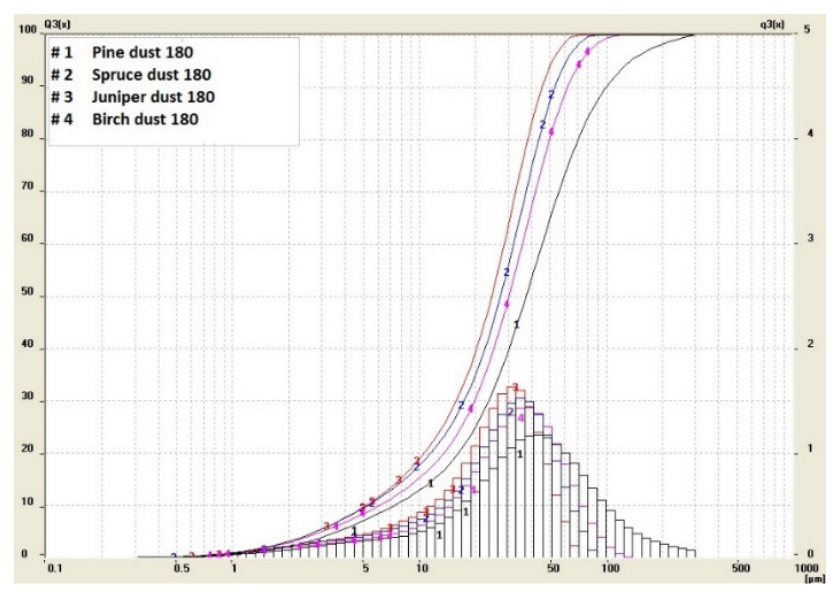

Fig.7. Dust particles distribution from grinding of different woods 180 grit sandpaper

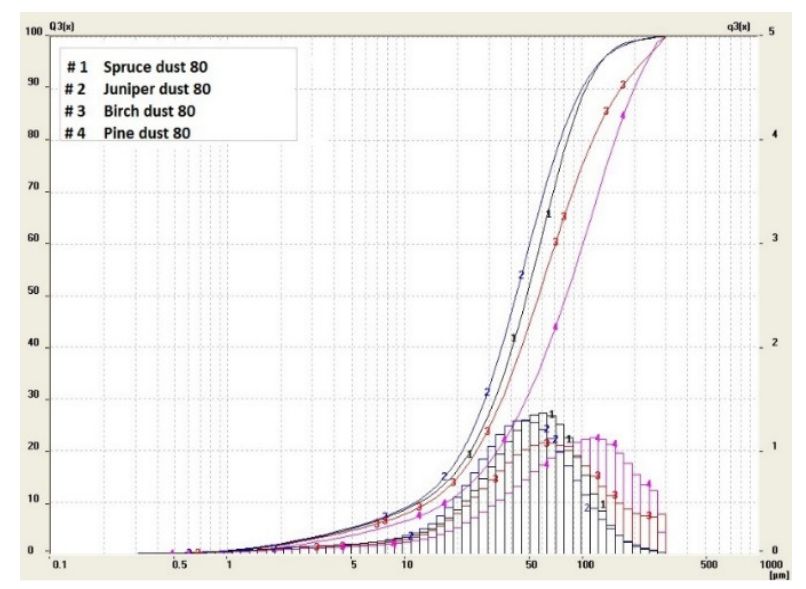

Fig.8. Dust particles distribution from phasing of different woods with 80 grit sandpaper

\subsection{Determination of risk levels}

The RA model for industrial rooms presented in Fig. 9 has been worked out. It is possible to link the health risk levels with the frequency of ME of workers working in hazardous conditions. The Estonian regulation of the Ministry of Social Affairs "Procedure for health examination of workers" [20] defines the health surveillance as follows: employee's health begins with the initial ME within the first month of the work activities and thereafter by the intervals indicated by the occupational physician, but not less than once every three years and for workers under 18 not less than once every two years. These demands are taken into account in the health risk assessment (HRA) model (Fig. 9, noted bold).

Occupational exposure limits (OEL) are set in order to protect the health of the workers working in hazardous conditions. OELs are concentrations of hazardous substances in the air, averaged over a specified period of time, referred to as a timeweighted average (8-hours work days and 40 hours per week). OEL is given in two types: as a long-term (8 hours) and short-term (15 minutes) limits. The last is settled for substances having a strong smell (like $\mathrm{NH}_{3}, \mathrm{or} \mathrm{CH}_{3} \mathrm{COOH}$ etc.). During the long-term period a variety of substances can't cause any health disorders during 8- hours work days and 40 hours per week. The short-time term exposure limits are set to help prevent effects such as eye or throat irritation, which may occur caused by exposure to the chemical during a few minutes [5].

Some illnesses caused by exposure to a complex of substances in the workplace may not appear at once, but after a long period of exposure (in the model Table 2, [10]), it has to be taken into account in the total assessment.

All activities in the work environment have to be preventive. Our new four-stage HRA model is presented in Fig. 9. The literature data and mainly the conclusions from $[9,10]$ presented in Table 2 are taken as the basis. The focal points in the model are border lines between the health risk levels.

B1 - the hazardous exposure to the worker begins: the border concentration value for chemicals is $10-50 \%$ of OEL or odors threshold; the exposure time is 8 hours for those who are not allergic to the substances present in the work environment. The latter have to undergo the consultation with medical specialists on the possibilities of continuing the work in this environment.

B2 - the border for the $2^{\text {nd }}$ health risk level. The concentration of substances are equal to OEL [11]. The summation in the case of mixture has to be taken into account (equation 1). The exposure time is 8 hours per day with compulsory use of personal protective equipment (PPE).

B3 - the border for the $3^{\text {rd }}$ health risk level. The concentration of a substance is equal to two times of OEL or the heighten of OEL is on $100 \%$. The PPE is compulsory and the exposure time is 4 hours per day.

B4 - the border for the 4th health risk level. The concentration of the chemical is four times of OEL, the exposure time 2 hours and PPE is compulsory. These actions will hopefully manage to keep worker's health.

Simultaneously to the HRA model the hazard statements have to be followed for each health risk level [24]:

$\mathbf{1}^{\text {nd }}$ HRL: H313, H335, H336

$2^{\text {nd }}$ HRL: H303, H305, H313, H316, H317, H333, H334, H 335, H336

$3^{\text {rd }}$ HRL: H302, H311, H312, H315, H320, H331, H332, H371, H372, H373

$4^{\text {th }}$ HRL: H 300, H 301, H304, H310, H314, H318, H319, H330, H340, H341, H342, H350, H351, H360, H362, H370. 

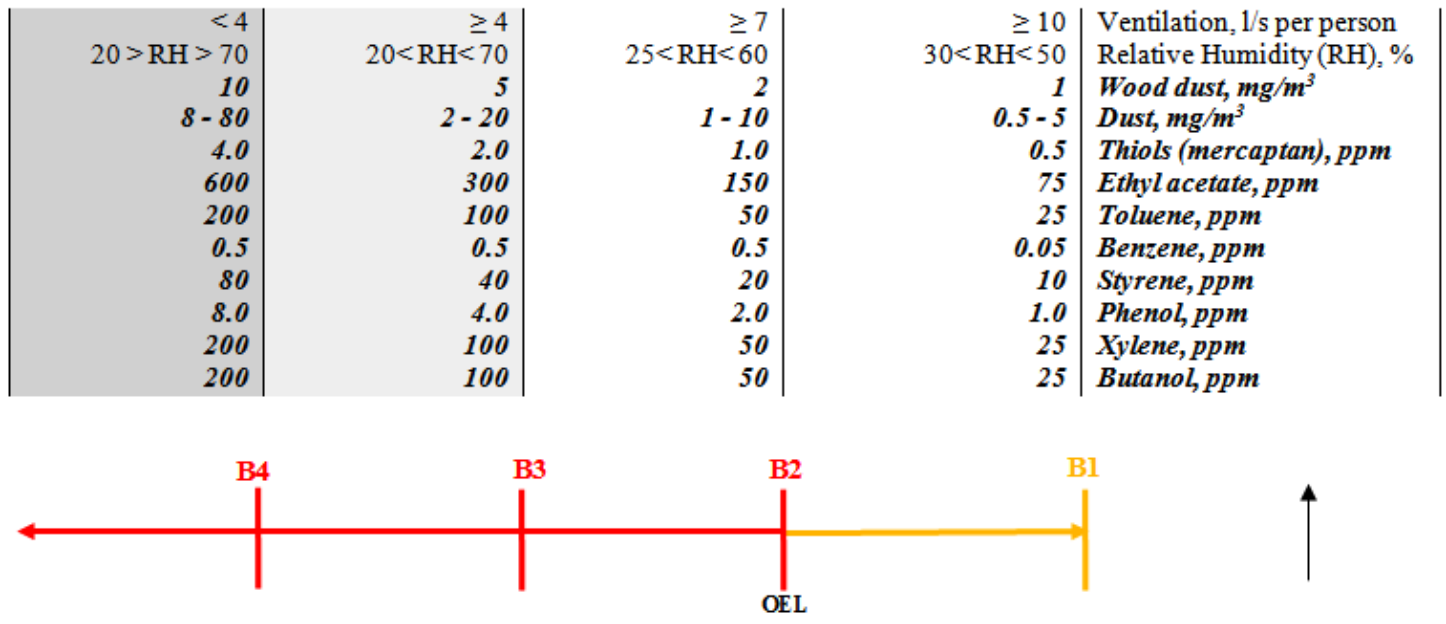

\begin{tabular}{|c|c|c|c|c|}
\hline $\begin{array}{l}4^{\text {th }} \text { health } \\
\text { risk level (HRL) }\end{array}$ & $\begin{array}{l}3^{\text {rd }} \text { health } \\
\text { risk level (HRL) }\end{array}$ & $\begin{array}{l}2^{\text {nd }} \text { health } \\
\text { risk level (HRL) }\end{array}$ & $\begin{array}{l}\mathbf{l}^{\text {st }} \text { health } \\
\text { risk level (HRL) }\end{array}$ & Variables \\
\hline $\begin{array}{r}{ }_{\mathrm{*}}^{*} \mathrm{~B} 4: \\
\text { OEL } \times 4 \\
\text { Exposure time: } 2 \text { hours }\end{array}$ & $\begin{array}{r}\text { B3: } \\
\text { c= OEL } \times 2 \\
\text { Exposure time: } 4 \text { hours }\end{array}$ & $\begin{array}{r}\text { B2: } \\
\mathrm{c}=\mathrm{OEL} \\
\text { Exposure time: } 8 \text { hours }\end{array}$ & $\begin{array}{r}\mathrm{Bl}: \\
\mathbf{c}=10-50 \% \text { of } \mathrm{OEL} \\
\text { or odor threshold } \\
\text { Exposure time: } 8 \text { hours }\end{array}$ & \\
\hline$M E^{* *}$ twice a year & ME** once a year & $\begin{array}{l}\text { ME**once in } 3 \\
\text { years }\end{array}$ & ME ${ }^{* *}$ once in 3 years & \\
\hline
\end{tabular}

*B4, B3, B2, B1 are borders between the health risk levels (1-4).

Fig. 9. Determination of health risk levels of dust and chemicals in industrial activities

The hazard statements are available on the labels of chemical packages and on the safety card of chemicals. Knowing the hazard statements and the HRA level in the work environment, the occupational health personnel are able to foresee the negative health effect on the workers.

The results of the measurement of dust and chemicals and the health risk levels according to the HRA model (Fig.9) are presented in Table 4.

Table 4. The results of measurement of dust and chemicals in the enterprises and the nearest dwellings

\begin{tabular}{|c|c|c|c|c|}
\hline $\begin{array}{l}\text { Measurement point An example of } \\
\text { a column heading }\end{array}$ & Measured value & The result, $\mathrm{C}$ & $\begin{array}{l}\text { Exposure limit } \\
{[11,22]}\end{array}$ & Health risk level (Fig.9) \\
\hline Country-place & dust & $0.016 \mathrm{mg} / \mathrm{m}^{3}$ & $0.050 \mathrm{mg} / \mathrm{m}^{3}$ & $1 \mathrm{st}$ \\
\hline Wood souvenirs making factory & dust & $0.09 \mathrm{mg} / \mathrm{m}^{3}$ & $5 \mathrm{mg} / \mathrm{m} 3$ & $1 \mathrm{st}$ \\
\hline Outside, close to the factory & dust & $0.011-0.014 \mathrm{mg} / \mathrm{m}^{3}$ & $0.050 \mathrm{mg} / \mathrm{m}^{3}$ & $1 \mathrm{st}$ \\
\hline Office-rooms (2) & dust & $0.012-0.014 \mathrm{mg} / \mathrm{m}^{3}$ & $0.050 \mathrm{mg} / \mathrm{m}^{3}$ & $1 \mathrm{st}$ \\
\hline Room for copies & dust & $0.02 \mathrm{mg} / \mathrm{m}^{3}$ & $0.050 \mathrm{mg} / \mathrm{m}^{3}$ & 2nd \\
\hline In the library & dust & $0.012 \mathrm{mg} / \mathrm{m}^{3}$ & $0.050 \mathrm{mg} / \mathrm{m}^{3}$ & $1 \mathrm{st}$ \\
\hline Offices, closed to the atrium & dust & $0.012 \mathrm{mg} / \mathrm{m}^{3}$ & $0.050 \mathrm{mg} / \mathrm{m}^{3}$ & $1 \mathrm{st}$ \\
\hline $\begin{array}{l}\text { Outside of the office house (in } \\
\text { town) }\end{array}$ & dust & $0.005 \mathrm{mg} / \mathrm{m}^{3}$ & $0.050 \mathrm{mg} / \mathrm{m}^{3}$ & $1 \mathrm{st}$ \\
\hline \multirow[t]{8}{*}{ Welding in metal industry } & $\mathrm{CrO}_{3}$ & $<0.1 \pm 0.05 \mathrm{mg} / \mathrm{m}^{3}$ & $2 \mathrm{mg} / \mathrm{m}^{3}$ & 2nd \\
\hline & $\mathrm{O}_{3}$ & $<0.05 \pm 0.0075 \mathrm{ppm}$ & $1 \mathrm{ppm}$ & $1 \mathrm{st}$ \\
\hline & Phenol & $<1 \pm 0.15 \mathrm{ppm}$ & $4 \mathrm{ppm}$ & $1 \mathrm{st}$ \\
\hline & Styrene & $<10 \pm 0.15 \mathrm{ppm}$ & $20 \mathrm{ppm}$ & $1 \mathrm{st}$ \\
\hline & $\mathrm{H}_{2} \mathrm{~S}$ & $<0.2 \pm 0.02 \mathrm{ppm}$ & $5 \mathrm{ppm}$ & $1 \mathrm{st}$ \\
\hline & Dust & $0.064 \ldots 0.668 \mathrm{mg} / \mathrm{m}^{3}$ & $5 \mathrm{mg} / \mathrm{m}^{3}$ & $1 \mathrm{st}$ \\
\hline & Swirling & $0.049 \ldots 0.25 \mathrm{mg} / \mathrm{m}^{3}$ & $5 \mathrm{mg} / \mathrm{m}^{3}$ & $1 \mathrm{st}$ \\
\hline & Welding & $0.038 \ldots 0.497 \mathrm{mg} / \mathrm{m}^{3}$ & $5 \mathrm{mg} / \mathrm{m}^{3}$ & \\
\hline Glass-wool manufacturing & dust & $3.7-20.0 \mathrm{mg} / \mathrm{m}^{3}$ & $10 \mathrm{mg} / \mathrm{m}^{3}$-overall dust & 4th \\
\hline Textile manufacturing & dust & $0.083-0.52 \mathrm{mg} / \mathrm{m}^{3}$ & $5 \mathrm{mg} / \mathrm{m}^{3}$ - inhalable dust & $1 \mathrm{st}$ \\
\hline \multirow{3}{*}{$\begin{array}{l}\text { Shale fuel oil handling, gaseous } \\
\text { phase }\end{array}$} & Benzene & $3.2 \mathrm{mg} / \mathrm{m}^{3}$ & $1.5 \mathrm{mg} / \mathrm{m}^{3}$ & $3 \mathrm{rd}$ \\
\hline & Toluene & $23.0 \mathrm{mg} / \mathrm{m}^{3}$ & $192 \mathrm{mg} / \mathrm{m}^{3}$ & $1 \mathrm{st}$ \\
\hline & o-Xylene & $35.0 \mathrm{mg} / \mathrm{m}^{3}$ & $200 \mathrm{mg} / \mathrm{m}^{3}$ & $1 \mathrm{st}$ \\
\hline
\end{tabular}




\begin{tabular}{lllll} 
& Phenol & $34.0 \mathrm{mg} / \mathrm{m}^{3}$ & $8.0 \mathrm{mg} / \mathrm{m}^{3}$ & 4 th \\
Rubber manufacturing for car seals & $\begin{array}{l}\text { Methyl } \\
\text { mercaptan }\end{array}$ & $50 \mathrm{ppm}$ & $1.0-10 \mathrm{ppm}$ & Sth \\
Opened car washing centres & Ethylene & $6.6 \mathrm{ppm}$ & Safe, not listed & \\
Car painting & m-xylene & $11,8 \mathrm{ppm}$ & $50 \mathrm{ppm}$ & $1 \mathrm{st}$ \\
& ethyl acetate & $17.6 \mathrm{ppm}$ & $150 \mathrm{ppm}$ & $1 \mathrm{st}$ \\
\hline
\end{tabular}

Occupational comfort depends also on the main indicators of the microclimate: air temperature, relative humidity, and air velocity. For example, higher humidity and lower temperatures will reduce the spread of dust or a chemical in the workroom. Working with chemicals, stronger draught regulation of ventilation is usually applied, which will cause excessive dry air in the work environment. Dry air, in turn, irritates eyes, nose and will increase the negative combined effect with chemical vapors.

\section{Conclusions}

The measurement of chemicals in the air of the work environment is the most difficult task in the occupational hygiene because of a complex of substances in the air; furthermore, the chemicals are unknown. In the current study two different methods: FTIR spectrometry and the Dräger express method were simultaneously used. It gave rather good results. We used innovative methods to determine of wood dust concentration in the air and the configuration and distribution of dust particles in the case of soft- and hardwoods.

Based on the measurements, new legislation on chemicals and dust, and literature data, the new four-stage health risk assessment model was worked out. Combined with the hazard statements, the model allows the occupational health professionals to carry out medical examinations (choose the right biomonitoring) and to diagnose occupational diseases in the early stage. The health risk levels in the model are connected with the frequency of medical examinations of persons working in the hazardous conditions.

Numerous workers in Estonia are exposed to wood dusts. Attention should be paid to the developing trend in the market of small and medium-sized enetrprises where the workers' conditions are relatively poor and the safety knowledge of employers is insufficient (produce of souvenirs or just an expensive, exclusive product, like a wooden bathtube). In addition, imported timber is used as well, the hazards of which may be unknown to the employer of small-scale enterprise. The comparison of Estonian softwood timber (pine, spruce and juniper) and hardwood timber (birch and alder) showed that larger part of PM1-PM10 is in softwoods. In addition, conifer dust is stickier due to its resin content, which means that PM4- PM10 can cause major health problems more easily, by attaching to the worker's upper respiratory tructs.

Based on the investigation, the exposure limits for softwood should not be heightened from 2 to $5 \mathrm{mg} / \mathrm{m}^{3}$, as it is in some other countries. Softwoods (juniper, spruce) have a larger fraction of small (< PM10) particles that is able to fasten in lungs and cause lung diseases. The selection and use of the adequate and suitable respiratory protective equipment has to be selected by the Guidance of Health and Safety Executive [21]. Regarding outside air around the industrial enterprises (e.g. wood processing), the concentration of dust was under the limits.

The problems are associated with the car washing point in the middle of a dwelling region. The smell and dust have caused complaints from the inhabitants.

In the rubber manufacturing where the plastic details for cars are produced, the problem is that safety cards give insufficient information of chemicals existing in the work environment during produce or handling, even it is difficult to predict what happens with the products at higher temperatures. Therefore the measurements with FTIR/FT-NIR and simultaneously with Dräger method are proved to be the only possibility in Estonian enterprises to identify the chemicals existing in the work environment and assess their hazardousness to the workers.

\section{Acknowledgements}

The work has been carried out with the help of the project SF0140022s10 "Chemical Engineering Aspects in Environmental Risk Assessment" (Estonia).

\section{References}

[1] Simanovska, J.; Bazbauers, G.; Valters, K. 2008. Legislative develöopments and ecodesign tools for reduction of chemical risks, Environmental and climate technologies 1: 81-84.

[2] Karlsson, R.; Luttropp, C. 2006. EcoDesign: what's happening? An overview of the subject area of EcoDesign and of the papers in this special issue. Journal of Cleaner Production 14(15-16): 1291-1298. http://dx.doi.org/10.1016/j.jclepro.2005.11.010

[3] Friesen, M. C.; Macnab, Y. C.; Marion, S. A. et al. 2006. Mixed models and empirical Bayes estimation for retrospective exposure assessment of dust exposures in Canadian sawmills, The Annals of Occupational Hygiene 50(3): 281-288. http://dx.doi.org/10.1093/annhyg/mei076 
[4] Reinhold K.; Tint P. .2009. Hazards profile in manufacturing: determination of risk level. Journal of Environmental Engineering and Landscape Management 17(2): 69-80. http://dx.doi.org/10.3846/1648-6897.2009.17.

[5] Workplace exposure limits (HSE). 2009. Online at: http://www.hse.gov.uk/pubns/priced/eh40.pdf

[6] Guidance for risk assessment at work. 1996. European Commission. Directorate- GeneralV, Luxembourg, 64 pp.

[7] British Standard Institution (BSI). BS 8800:1996. Guide to occupational health and safety management systems, London, 40 pp.

[8] British Standard Institution (BSI). BS 8800:2004. Occupational health and safety management systems - Guide, London, 69 pp.

[9] Rantanen, S. 2001. Chemical risk assessment. Days of Occupational Health 23-24.10.2001. Finnish Institute of Occupational Health, Helsinki, 38-42 (in Finnish).

[10] Tint, P.; Reinhold, K.; Tuulik, V. 2004. Risk assessment of chemicals affecting the central nervous system, in HFES Europe Chapter Proceedings Maastricht, Shaker Verlag, 251-254.

[11] Resolution of the Estonian Government No.223 of 23 October 2007 on the exposure limits of chemical agents in the work environment. State Gazette in Estonia, RTL 2007, 55, 369.

[12] Bake, M. A.; Eglite, M.; Martinsone, Z.; Buike, I.; Pike, A.; Sudmalis, P. 2010. Organic solvents as chemical risk factors of the work environment in different branches of industry and possible impact of solvents on workers' health, Proceedings of the Latvian Academy of Sciences Section B, 64(1/2)(666/667): 25-32.

[13] Tint, P.; Traumann, A. 2012. Health risk assessment in atrium-type buildings, International Journal of Energy and Environment 6(4): 389-396.

[14] Traumann, A.; Tint, P.; Tuulik, V. 2012. The indoor air quality in educational institutions, Environmental Engineering and Management Journal 11(1): 207-214.

[15] Centers for Disease Control and Prevention (CDC). 2014. Online: http://www.cdc.gov/niosh/pel88/wooddust.html.

[16] Orru, H.; Maasikmets, M.; Lai, T.; Tamm, T.; Kaasik, M.; Kimmel, V.; Orru, K.; Merisalu, E.; Forsberg, B. 2010. Health impacts of particulate matter in five major Estonian towns: main sources of exposure and local differences, Air Qual Atmos Health, Online 11 June 2010.

[17] Kauppinen, T.; Vincent, R.; Liukkonen, T. 2006. Occupational exposure to inhalable wood dust in the member states of the European Union, Ann. Occup. Hyg. 50: 549-561. http://dx.doi.org/10.1093/annhyg/mel013

[18] Vanadziens, I.; Eglite, M.; Bake, M. A.; Sprudza, D.; Martinsone, Z.; Martinsone, I.; Rusakova, N.; Pike, A.; Sudmalis, P. 2010. Estimation of risk factors of the work environment and analysis of employees' self estimation in the wood processing industry. 2010, in Proceedings of the Latvian Academy of Scinces, Section B, vol. 64(1/2)(666/667): 73-78.

[19] Peterson, E.; Shaurette, D.C.; Demolition dust: hazards and control. Dust Control Technology. http://www.dustboss.com/support/dust-related-healthsafety-issues/demolition-dust-hazards-and-control/

[20] Resolution of the Ministry of Social Affairs No 74 of 24 April 2003 on the Procedure for health examination of workers, State Gazette in Estonia, RTL, 2003, 56, 816.

[21] Respiratory protective equipment at work. 2013. A practical guide. Health and Safety Executive. HSG53.

[22] Resolution of the Ministry of Environmental Affairs. No 43 of 08 July 2011 on the ambient air pollution level of the limit values and pollution tolerance limits, State Gazette in Estonia, RTI, 12.07.2011.

[23] Principal effect(s) of exposure to substances, listed by OSHA Health Copde and Health Effects. 2008. Field Operation manual, OSHA Insturction CPL 2.45B, chapter IV,Online at: http://www.osha.gov/dts/chemicalssampling/field.html

[24] Documentation for Immediately Dangerous To Life Concentrations (IDLHs). NIOSH. 1995. Online at: http://www.cdc.gov/niosh/idlh/idlhintr.html

[25] Regulation of the European Parliament and of the Council on the classification, labelling and packaging of substances and mixtures, and amending Directive 67/548/EEC and Regulation (EC) No 1907/2006. Brussels, 27.06.2007. Commission of the European Communities. 